\title{
About ATMPs, SOPs and GMP: The Hurdles to Produce Novel Skin Grafts for Clinical Use
}

\author{
Fabienne Hartmann-Fritsch ${ }^{\mathrm{a}, \mathrm{b}}$ Daniela Marino ${ }^{\mathrm{a}, \mathrm{b}} \quad$ Ernst Reichmann ${ }^{\mathrm{a}, \mathrm{b}}$ \\ a Tissue Biology Research Unit, Department of Surgery, University Children's Hospital Zurich, Zurich, Switzerland; \\ ${ }^{b}$ Children's Research Center, University Children's Hospital Zurich, Zurich, Switzerland
}

\section{Keywords}

Bio-engineered skin grafts · ATMP · GMP · Clinical trials

\section{Summary}

Background: The treatment of severe full-thickness skin defects represents a significant and common clinical problem worldwide. A bio-engineered autologous skin substitute would significantly reduce the problems observed with today's gold standard. Methods: Within 15 years of research, the Tissue Biology Research Unit of the University Children's Hospital Zurich has developed autologous tissue-engineered skin grafts based on collagen type I hydrogels. Those products are considered as advanced therapy medicinal products (ATMPs) and are routinely produced for clinical trials in a clean room facility following the guidelines for good manufacturing practice (GMP). This article focuses on hurdles observed for the translation of ATMPs from research into the GMP environment and clinical application. Results and Conclusion: Personalized medicine in the field of rare diseases has great potential. However, ATMPs are mainly developed and promoted by academia, hospitals, and small companies, which face many obstacles such as high financial burdens.

(C) 2016 S. Karger GmbH, Freiburg

\section{About denovoDerm and denovoSkin}

Background

The treatment of severe full-thickness skin defects resulting from burns, congenital giant nevi, disfiguring scars, soft tissue trauma, and tumor resection represents a significant and com- mon clinical problem worldwide. Most autologous skin grafting techniques applied today are based on transplanting split-thickness skin from a donor site to the area of the defect. A significant problem using split-thickness skin is often the fact that donor sites for harvesting split-thickness skin are limited, especially if large skin defects have to be covered. An additional drawback of this method is the structure of split-thickness skin. It contains all of the epidermis, but only remnants of the dermis. This lack of dermal tissue frequently leads to significant scarring and wound contraction due to the lack of dermal regeneration within the wound area, resulting in non-ideal outcomes regarding functionality and cosmetics [1-4]. Therefore, split-thickness skin is often used in combination with a dermal template, such as Integra artificial skin [1, 3, 5-9], Matriderm ${ }^{\circledR}$ (MedSkin Solutions Dr. Suwelack, Billerbeck, Deutschland) $[4,10,11]$, or other collagenelastin scaffolds [2].

The above mentioned problems could be significantly reduced if a bio-engineered autologous skin substitute would be available.

\section{Development of denovoDerm and denovoSkin}

The Tissue Biology Research Unit of the University Children's Hospital Zurich has developed in 15 years of research, in close collaboration of scientists and clinicians, autologous tissue-engineered skin grafts based on a collagen type I hydrogel which can be applied in one surgical intervention. These skin grafts have successfully been tested in pre-clinical studies [12-14]. Since 2013, the developed skin grafts are produced in the facilities of the Wyss Translational Center Zurich, Switzerland, under good manufacturing practice (GMP) conditions for clinical trials. In June 2014, a phase I clinical trial [15] was started at the University Children's Hospital Zurich with the following two products (fig. 1):

- denovoDerm, an autologous tissue-engineered dermal graft used in combination with autologous split-thickness skin intraoperatively.

\section{KARGER}

() 2016 S. Karger GmbH, Freiburg

Fax +497614520714 
Fig. 1. Overview on the production process of (A) denovoDerm and (B) denovoSkin. A A skin biopsy is removed from the patient and dermis and epidermis are separated. Fibroblasts are isolated and incorporated in a collagen type I hydrogel. The dermal substitute denovoDerm is transplanted onto the wound bed and covered with split-thickness skin. B For denovoSkin, a skin biopsy is removed from the patient and dermis and epidermis are separated. Fibroblasts and keratinocytes are isolated. Fibroblasts are incorporated in a collagen type I hydrogel. After a cultivation phase, keratinocytes are seeded on top of this hydrogel. The dermo-epidermal skin substitute denovoSkin is transplanted onto the wound bed and does not require additional covering due to the epidermal cell layer on top of the hydrogel.

A

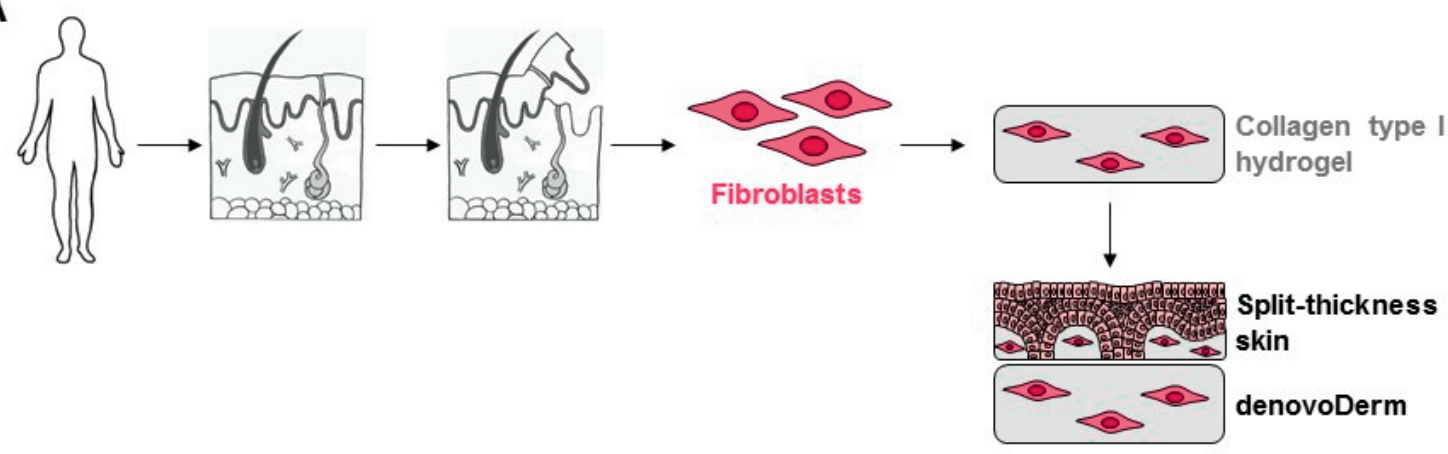

B

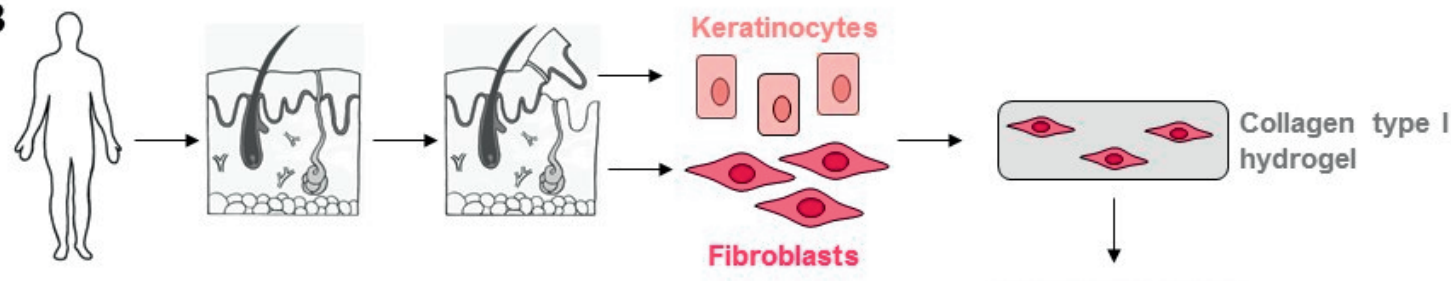

बणनणणणव०

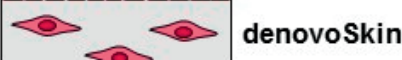

- denovoSkin, an autologous tissue-engineered dermo-epidermal skin graft. As it includes a keratinocyte layer on the upper side, it does not need any additional coverage by split-thickness skin.

Both products are transplanted in a one-step surgery directly onto the wound bed [15].

\section{Advanced Therapy Medicinal Products (ATMPs)}

\section{Definition of ATMPs}

ATMPs are defined as medicinal products for human use which are either based on gene therapy, somatic cell therapy, tissue engineering, or a combination of those. The previously described products denovoDerm and denovoSkin belong to this category, as a tissue-engineered product is defined as a product containing or consisting of engineered cells or tissues (from human and/or animal origin, viable or non-viable) and having properties used for regeneration, repair or replacing human tissue. In this context, the label 'tissue engineering' is fulfilled if cells or tissues were substantially manipulated to achieve the desired biological characteristics, physiological functions, or structural properties relevant for the planned mode of action.

The field of ATMPs underwent large growth and changes in the past years. In many areas of medicine, new techniques and methods offer novel therapeutic approaches with the help of such products.
With the introduction of the ATMP regulation of the European Medicines Agency [16], the legal framework for ATMPs was standardized in Europe:

- Centralized procedures for ATMPs were introduced.

- The Committee for Advanced Therapies (CAT) was established.

- Tissue engineering was clearly defined.

- Cell-based products were clearly regulated.

Regarding manufacturing and testing of ATMPs, the ATMP regulation EC 1394/2007 [16] defines the standard. The manufacturing of ATMPs should be performed under conditions following the guidelines for GMP. The principles of GMP are described in the Commission Directive 2003/94/EC [17].

For quite some time, the status and classification of ATMPs in Europe was unclear, and significant variations among the different member states were observed [18]. This unsatisfactory situation was substantially improved by the introduction of the ATMP regulation, and by the establishment of the CAT by the EMA in January 2009. This multidisciplinary committee is responsible for assessing the quality, safety, and efficacy of ATMPs. Nevertheless, situations occur where national competent authorities of EU member states differ in the ATMP classification of a specific product [19].

\section{Development of ATMPs}

It appears that presently research and development of ATMPs is almost exclusively performed by academia, hospitals, and small 
Table 1. Tissue-engineered ATMPs for skin defects

\begin{tabular}{|c|c|c|c|c|}
\hline Product & Manufacturer & Active substance & Indication & Status \\
\hline \multicolumn{5}{|l|}{ Allogeneic } \\
\hline Apligraf $[23]$ & Organogenesis, USA & $\begin{array}{l}\text { allogeneic fibroblasts and } \\
\text { keratinocytes in collagen matrix }\end{array}$ & ulcers & $\begin{array}{l}\text { commercially available } \\
\text { in the USA }\end{array}$ \\
\hline Dermagraft $[61]$ & Organogenesis, USA & $\begin{array}{l}\text { allogeneic fibroblasts on } \\
\text { polyglactin }\end{array}$ & $\begin{array}{l}\text { diabetic foot } \\
\text { ulcer treatment }\end{array}$ & $\begin{array}{l}\text { commercially available } \\
\text { in the USA }\end{array}$ \\
\hline FirstCover [62] & $\begin{array}{l}\text { Elanix Biotechnologies } \\
\text { AG, Switzerland }\end{array}$ & $\begin{array}{l}\text { fetal fibroblasts and } \\
\text { keratinocytes in matrix }\end{array}$ & $\begin{array}{l}\text { acute skin } \\
\text { wound care }\end{array}$ & in development \\
\hline \multicolumn{5}{|l|}{ Autologous } \\
\hline $\begin{array}{l}\text { Engineered skin substitute } \\
\text { (Permaderm })[64,65]\end{array}$ & $\begin{array}{l}\text { Amarantus BioSciences, } \\
\text { USA }\end{array}$ & $\begin{array}{l}\text { autologous fibroblasts and } \\
\text { keratinocytes in collagen matrix }\end{array}$ & severe burns & $\begin{array}{l}\text { in development } \\
\text { ODD for the treatment of } \\
\text { severe burns granted by FDA }\end{array}$ \\
\hline Tisscover $[25,66]$ & A-Skin, The Netherlands & fibroblasts and epidermal sheet & ulcers & in development \\
\hline $\begin{array}{l}\text { Self-assembled skin } \\
\text { substitute }[67,68]\end{array}$ & $\begin{array}{l}\text { CHU de Québec, } \\
\text { Université Laval, Canada }\end{array}$ & fibroblasts and keratinocytes & large burns & in development \\
\hline Epicel $[63]$ & Vericel Corporation, USA & autologous keratinocytes & large burns & commercially available in USA \\
\hline denovoDerm [15] & $\begin{array}{l}\text { Tissue Biology Research } \\
\text { Unit, University of } \\
\text { Zurich, Switzerland }\end{array}$ & fibroblasts in collagen hydrogel & skin defects & in development \\
\hline denovoSkin [15] & $\begin{array}{l}\text { Tissue Biology Research } \\
\text { Unit, University of } \\
\text { Zurich, Switzerland }\end{array}$ & $\begin{array}{l}\text { fibroblasts in collagen hydrogel } \\
\text { and keratinocytes }\end{array}$ & skin defects & $\begin{array}{l}\text { in development } \\
\text { ODD for the treatment of burns } \\
\text { granted by EMA and Swissmedic }\end{array}$ \\
\hline
\end{tabular}

companies. $80 \%$ of ATMPs currently under development are from academia [20]. Large pharma companies cannot be considered to be relevantly involved in the ATMP field [21], probably because niche products such as ATMPs are not very appealing for those. Especially for small ATMP developers the overview, deep understanding, and implementation of ATMP regulations and guidelines can be challenging. It has been argued that the ATMP standards, which were developed in collaboration with the pharmaceutical industry, would not always be compatible with the typical niche applications of ATMPs, as most of them are of autologous nature and produced per patient (or in very small batch sizes), making the upscaling extremely demanding [18]. Additionally, the workload generated by the standards of GMP and good clinical practice (GCP) is often underestimated [18]. Interestingly, a survey at European research centers working with ATMPs showed that most of the participating centers supported strict and careful ATMP regulation. None of the centers in this survey supported potential lower GMP standards for ATMPs than standard medicines or lower standards for academic groups [22].

\section{Examples of Commercially Available ATMPs and ATMPs under Development}

Several ATMP products for skin defects are commercially available. Some examples are described in the following. The product Apligraf $^{(}$(Organogenesis Inc., Canton, MA, USA) for the treatment of ulcers consists of keratinocytes and fibroblasts in a collagen matrix. In contrast to denovoSkin, the cells are from allogeneic origin [23]. The product Dermagraft ${ }^{\circledR}$ (Organogenesis Inc.) consists of allogeneic fibroblasts in a polyglactin matrix and is used for the treatment of diabetic foot ulcers [24]. Epicel ${ }^{\circledR}$ (Vericel, Cambridge, MA, USA) consists of autologous keratinocytes and is used for the treatment of large burns [24]. Currently in a phase II trial is the product Tiscover ${ }^{\circledR}$ (A-SKIN, Amsterdam, The Netherlands) for the treatment of chronic wounds, consisting of autologous keratinocytes and fibroblasts. In contrast to denovoSkin, it is only available in small size [25]. Table 1 gives an overview on tissue-engineered ATMPs for skin defects.

\section{Hurdles to Produce ATMPs under GMP Conditions}

\section{Translation of a Research Process into a GMP Process}

The translation of a successful research process into a process following the GMP guidelines is very challenging for a research group. Every small step of the perfectly established manufacturing process has to be analyzed for its suitability to the GMP production process. Adaptations have to be made at different levels, which are described in more detail in the following paragraphs.

\section{Risk Management}

Every team working on the translation of a research process into the GMP environment will have to deal with many risks throughout the process. Risks can affect any area of the process. It can include materials, i.e. that not all required material is available in GMP grade; risks for involved personnel, i.e. working with living tissue as starting material poses risks of transmitting pathogens to 
staff or cross-contaminating other batches; or risks for the patients if for example the batch manufacturing has to be stopped due to contamination. Careful risk management ensures quality of the manufacturing process and ultimately safety of the patient [26]. General risk management includes the assessment, control, communication and review of risks. Of advantage is a multidisciplinary team to perform risk management as they will bring different aspects into the discussions.

Risk management tools are valuable instruments to identify risks, their cause and effects, and possible measures to minimize it. A commonly used tool is the risk assessment based on the method of failure modes and effects analysis (FMEA). It is a systematic technique for assessing the risk of each component of a system, originally designed by the American army [27]. A complex process such as the manufacturing of an ATMP is divided into small manageable production steps (e.g., starting materials, consumables, handling techniques, and equipment used). Possible failures for all steps with effects, causes, and possibilities of detecting the failures are listed. Scores are given according to severity, probability of occurrence, and probability of detection. Based on those scores, a risk priority number is calculated. According to a previously defined threshold for the risk priority number, actions to reduce the risk have to be taken. [27-29]

\section{Documentation}

Documentation is crucial to GMP [30]. It assures the traceability in case of batch-specific problems, reduces the risk of mistakes by defining the complete process, ensures reproducibility, and confirms responsibilities by signatures. A precise and detailed documentation system has to be established, describing the complete manufacturing process [31]. This not only includes the manufacturing steps of the ATMP itself but also preparation protocols for culture media, solutions, and matrixes. Additionally, all used materials (starting materials and consumables) need to be described in detail. The documentation system can be structured on different levels, for example into standard operating procedures (SOPs), working instructions (WIs), and protocols.

SOPs describe the frame and context of a standard process and general requirements. They are detailed, in line with actual practice, easy to understand, chronological, explicit, versioned, revised, and released. WIs describe one specific step in very detail. Protocols are generated to document the performed work.

The complete manufacturing process for an ATMP will be described in an investigational medicinal product dossier (IMPD) [32].

\section{Starting Materials}

Almost all starting materials used in research are declared by the manufacturer as 'research use only'. As certain product certificates may not be available, the use of those materials under GMP conditions may only be approved by the authorities under special circumstances, meaning if no other option is available and on a risk-based assessment (for example according to FMEA). In the past years, GMP-grade materials have become more and more available. Additionally, many companies offer the production of
GMP-grade materials based on customer request. However, those custom-made products are on a higher pricing level than the standard materials, which may be problematic for academia and ATMP production with low production volume. Modifying starting materials from research grade into GMP grade requires meticulous testing of the new material for suitability.

Of special interest as starting material is the human tissue sample. It represents the core material for the ATMP production but at the same time it is the material with the highest variability and all but impossible to standardize. Before tissue removal, the following laboratory analysis have to be performed: HIV 1, HIV 2, HBV, $\mathrm{HCV}$, and syphilis are minimally required, depending on the type of tissue and donor; additional tests can be mandatory [33]. It is advisable to provide detailed protocols on tissue sample removal. Nevertheless, the quality of incoming tissue might vary depending on the performing person, but mainly depending on the donor. Factors such as age, sex, donor area, metabolic activity, and interdonor variability will all influence the manufacturing process, but cannot be circumvented. The manufacturing process has to be stable enough to deal with this high variability of starting material, and manufacturing protocols should allow for minimal variations depending on the starting material. Additionally, In-process controls (IPCs) should account for this variability, especially when defining thresholds for acceptance criteria.

Careful evaluation of the material origin is required when using bovine material, as widely used in cell culture applications $[32,34$, 35].

\section{Consumables}

For manufacturing according to the GMP guidelines, single-use consumables are the first choice. Standard research consumables often are delivered in large quantities and multipacks. However, for GMP single-use single-packed sterile consumables are ideal and ease the routine production as no cleaning has to be performed and therefore the risk of cross-contamination can be minimized.

Re-usable material has to be checked carefully for its suitability for application under GMP conditions, with special regard to the risk of cross-contamination. Efficient cleaning has to be performed and validated, requiring material resistance to the chosen cleaning agent and cleaning method. Validated sterilization processes, in combination with the appropriate packaging, ensure the safety of the material.

IPCs

IPCs have to be established for the complete manufacturing process; they are used to address questions of two main categories: i) the safety of the product and ii) the quality of the product [36].

IPCs of the first category are used to ensure the safety of the product, certifying that for example a cell population used for the production of a tissue-engineered product is free of endotoxins and mycoplasma. Of course sterility is a parameter broadly and carefully checked. IPCs for the product quality are used to confirm that the manufactured product will correspond to the product authorized by the regulatory authority. For example, cell populations 
have to be analyzed on their identity and purity to ensure the appropriate cells can be found in the final product in the defined number.

Controls based on the experience of the manufacturing staff are widely used in research; however, under GMP conditions such controls are difficult to perform in a standardized way and difficult to reproduce. Additionally, the outcome of a GMP manufacturing process should not depend on the manufacturing staff. Whenever possible, objective controls with measurable outcomes should be chosen. As an example, the microscopic assessment of the cell morphology of a population as identification tool should be replaced by immunofluorescence analysis, using specific markers for the cell type under investigation.

The establishment of such an IPC plan should be considered early in the translation of the research process into a GMP process, as the introduction of IPCs at different manufacturing steps might influence the further proceeding; for example, significantly higher initial cell numbers are required if flow cytometry quality analyses have to be performed.

Additional costs generated by IPCs may not be underestimated as such controls usually have to be performed in a GMP-accredited laboratory.

\section{Release Controls}

In addition to the IPCs conducted throughout the process on intermediate products and quality control samples, also the final product has to be analyzed for safety and quality by a so-called qualified person $(\mathrm{QP})$. However, under routine production conditions this is often not possible as analyzing methods are destructive or can be done only under non-sterile conditions. Therefore a plan has to be established specifying on which samples all required controls can be executed. Validations have to be undertaken to ensure that the analyzed samples are representative for the final product.

Particular attention should be paid on the strategy regarding sterility of the final product. Widely used sterility methods, such as methods used for sterilization of medical devices or healthcare facilities (e.g., autoclave steam sterilization, ethylene oxide sterilization, or gamma ray sterilization $[37,38]$ ), are not applicable for living tissues. Hence, as no final sterilization can be performed, sterility of the product has to be ensured during manufacturing, from starting materials to packaging materials for the final ATMP product [39]. In addition to routine sterility tests during manufacturing, it is advisable that also the final product is analyzed for sterility, for example according the European Pharmacopoeia [40]. It should be taken into consideration that sterility analysis using the direct inoculation method will take approximately 14 days. When dealing with living ATMPs with their relatively short shelf life, clinical application of the batch might therefore take place before final sterility results are available, which will lead to a conditional release of the ATMP for transplantation. Other required release controls regarding product safety can include analysis for mycoplasma [41, $42]$ and endotoxins $[43,44]$.

In addition to safety analysis of the final product, analysis regarding the functionality and performance should be included. De- pending on the type of ATMP, this could comprise of the geometrical structure of the product, the amount of living cells, the concentration of secreted factors, or any other component that is considered to be the active ingredient or mode of operation of the ATMP, as described in the IMPD.

\section{Training of Staff}

A crucial point for a successful GMP process is the staff [45]. The quality of the product is defined by the implementation of all documentation, protocols and controls by qualified staff with extraordinary diligence. Training procedures involve training in standard GMP procedures, GMP facility-specific instructions such as hygiene measures, cleaning and monitoring, as well as extensive training on all documentation specific for the production process.

\section{Approval by the Regulatory Authority}

After successful establishment and validation of the entire GMP process, including methods, IPCs and release controls, the manufacturing process has to be approved by the regulatory authority.

The basis for approval by the regulatory authority is the investigational medicinal product dossier (IMPD). It serves as core document for the complete manufacturing process and describes information regarding quality, manufacture, and control of the investigational product. The structure of an IMPD is set out in the 'Guideline on the Requirements to the Chemical and Pharmaceutical Quality Documentation Concerning Investigational Medicinal Products in Clinical Trials' [46] in connection to the Directive 2001/20/EC [47].

\section{Hurdles to Applying ATMPs in the Clinic}

For notification of a clinical trial with an ATMP, an extensive dossier on the ATMP product has to be submitted to the regulatory authorities, including profound pre-clinical data [48-50].

As also shown by Pearce et al. [22], this leads to the use of farfetched animal models [51]. To perform pre-clinical testing on ATMPs, animal testing is standard, though the choice of the appropriate small and large animal model is challenging. ATMPs are based on human-specific (cell) sources and modes of action. However, a human-specific ATMP is either tested in an immune-incompetent system, or for immune-competent application the ATMP has to be transformed into an animal-specific (animal autologous) ATMP. When using immune-incompetent animals, such as nu/nu mice or rats [14, 52], it has to be taken into account that functionality of the applied cells or bio-engineered tissues might differ from human application. Toxicity of human-specific biological material might be under- or overestimated due to species-specific side effects and pharmacologic activity. In addition, the enormous difference in life span may alter the results. When using immune-competent animals, as for example the pig as we did for the large-scale proof-ofconcept for denovoDerm and denovoSkin $[53,54]$, changes in raw materials such as cell culture media and growth factors for the production of the animal-specific ATMP may introduce a source of in- 
accuracy to the test system. The study of Pearce et. al. [22] therefore suggests a paradigm shift in pre-clinical ATMP testing, suggesting first-in-man data to be used as part of the dossier for clinical trial authorization. Such first-in-man data, also referred to as phase 0 study, then might be followed by a classic phase I trial.

A phase I trial is designed to assess the safety of the investigational product and to identify possible side effects [55]. For a clinical phase I trial with a new product usually healthy, adult volunteers are recruited [56]. The main outcome for a phase I trial is safety, meaning it has to be shown that the investigational product can be applied without safety concerns.

Due to the nature of the tissue-engineered products denovoDerm and denovoSkin, this traditional set-up for the phase I trial was not appropriate. No healthy volunteers could be used, as the transplantation of the skin substitutes are only indicated on preexisting and severe skin defects, which are absent in healthy volunteers. For obvious reasons creation of such a skin defect would be unethical. Children would benefit the most of a tissue-engineered skin substitute as they still grow, and scar tissue has extremely inelastic properties. Therefore, it was a straight-forward approach to go for the phase I trial directly into the population that would also gain most benefit of this innovative method.

This unconventional phase I design combined with the vulnerable patient population asked for a close dialogue and collaboration with the regulatory authorities and especially with the local ethical commission.

Establishing an independent data safety monitoring board (IDSMB) ensured an objective and unbiased point of view on the trial result, ensuring patient safety was warranted at any time of the trial. The IDSMB ideally is composed of experts from different fields such as ethics and the medical area of the investigational indication to fully interpret and evaluate the safety of the study participants. Each member of the IDSMB must be completely independent and non-related to the trial. To avoid possible conflicts of interest, the members should not have any financial or other interest that might influence objective data review and recommendations. The IDSMB serves to advise the sponsor and principal investigator of a trial with their expertise and recommendations.

The IDSMB has unrestricted access to all trial documents and source data at any time point. At critical steps of the trial, the IDSMB reviews the so far gained data and gives recommendations for the further procedure.

\section{Hurdles to Clinically Apply ATMPs in Europe}

According to the ATMP regulation, an investigational medicinal product for application in clinical trials must be formally released for application by a QP. QPs are approved by the regulatory authority and often have a pharmaceutical background. An issue identified by Pearce et al. [22] and also observed by us [57] is the hesitation of QPs to take over responsibility for releasing an ATMP, as such products may not be part of their area of expertise. While we are in the comfortable situation that denovoDerm and denovoSkin products are manufactured in a certified GMP facility in Zurich [58] including release by a QP, difficulties were encountered when arranging import of the ATMPs to The Netherlands for an international multicenter clinical trial. Although formally released in Switzerland by an approved QP, for application of the products in The Netherlands the products need a second formal release after import by a local QP. Several QPs across The Netherlands refused the collaboration, and finding an appropriate solution was extremely timeconsuming. Additionally, hiring a QP for release of a single-batchsized patient-specific ATMP is extremely expensive and a logistic challenge due to the short shelf life of the products.

Transport of ATMPs across Europe is feasible, but poses high financial burdens on academic research groups. Due to the living nature of ATMPs, transport conditions require short transport times and controlled transport conditions, which often involve a tempered transport. Therefore, the collaboration with an appropriate, ideally experienced logistic partner is essential for the successful transport of ATMPs.

\section{Orphan Drug Designation (ODD): Dealing with Regulatory Agencies}

In several countries, including the EU, regulations for orphan drugs have been introduced, with the goal to stimulate research and development to foster the treatment of rare diseases. Significant benefits can be achieved for products with an indication for the treatment of rare diseases. If certain criteria are fulfilled, ODD of a product can be granted, in the EU by the European Medicines Agency Committee for Orphan Medicinal Products (COMP). In the USA, this is the Office of Orphan Products Development (OOPD), a branch of the FDA, and in Switzerland the ODD is handled by Swissmedic. The procedures for ODD in the USA and the EU are to a certain degree harmonized, but several differences still remain in the procedure [59]. For COMP ODD, the criteria to be met include [50, 60]:

- Intention for the treatment, prevention or diagnosis of a disease that is life-threatening or chronically debilitating

- Prevalence of condition in the EU and Switzerland $\leq 5 / 10,000$ patients, $<200,000$ patients/year in the US, or it is unlikely that marketing of a given medicine would generate sufficient returns to justify investment for development

- No satisfactory method of diagnosis, prevention or treatment of condition or significant benefit to those affected by condition.

Benefits when receiving the ODD include incentives from the EU to develop a medicine for a rare disease such as reduced fees, fast track approaches to market authorization, and extended market protection.

\section{Commercialization of ATMPs}

The production and commercialization of allogeneic skin ATMPs has been achieved in the recent past $[23,61]$ and will be 
achieved in the near future [62]. These products are indeed living off-the-shelf products that can be manufactured using donor cells from biobanks, stored for relatively long time, and shipped without major hurdles. Epidermal autologous skin grafts [63], i.e. very simple and thin sheets produced starting off from patient's material, have also entered the market, reaching, however, only a very small patient population, the severe burn patients with no real alternative therapeutic option. The poor clinical performance (severe scarring results after transplantation of epidermal sheets) and the high fragility have negatively impacted the market penetration and thus the economic value, of these products. In contrast, the autologous dermo-epidermal skin grafts (table 1) have not yet reached the commercialization phase as they all are still in the process of obtaining their clinical validation. Nonetheless, these grafts have entered the small-scale GMP production stage, and, clearly, the manufacturing process is costly. All kinds of autologous ATMPs (be it bone, cartilage, cornea or skin) face the same challenge, but the autologous ATMPs represent the real breakthrough in regenerative medicine. A robust price analysis based on market potential, competitive value, patient benefits / lack of existing technologies, and long-term healthcare savings must be run at a very early stage. In parallel, the reimbursement activities must be initiated to build up a constructive interface between manufacturer and health technology assessment organizations on a national level (in EU at least) with the aim of defining and implementing an effective reimbursement strategy. An example of success is represented by the first autologous ATMP approved by EMA, Chondrocelect ${ }^{\circledR}$ (TiGenix (Leuven, Belgium), priced at ca. EUR 29,000.00 per injection), as for today, which is reimbursed in The Netherlands, UK, Germany, Spain, and Belgium.

While, at least in Europe, there are a few possibilities to obtain funds to perform first-in-man trials (EU and nationals grants), little grant money, if any, is available to finance the necessary but very expensive clinical trials as well as the regulatory, reimbursement and marketing activities. A non-profit academia entity may represent an option, but such platforms are not easy to be established since a substantial financial contribution would need to be acquired via charity and/or government agencies. Furthermore, these kinds of platforms may slow down the development process (due to scarce financial resources) and strongly limit the patient access to the technology. Thus, the creation of small and mediumsized enterprises (SMEs) may represent an attractive solution to proceed with the product development in a faster and stable manner. Clearly, the survival of such SMEs cannot be not solely linked to the treatment of the orphan burn indication. A robust business plan may further include the targeting of larger markets such as reconstructive and plastic surgery, chronic ulcers as well as cosmetics.

\section{Conclusion}

The successful production of ATMPs for clinical application has to deal with many obstacles. Financial burdens often pose significant risks to the ATMP project, especially when undertaken by academia or SMEs. Finding the right partners is essential, as it is difficult for small manufacturers to establish some of the required aspects, such as GMP production. Despite the long list of hurdles, personalized medicine in the field of rare diseases has great potential and, if successful, may have a major impact on the welfare of affected patients.

\section{Funding Sources}

The research leading to these results has received funding from the Clinical Research Priority Programs (CRPP) of the University of Zurich, Switzerland, from the European Union's FP7 Programme for Research, Technological Development and Demonstration (FP7/2011-2016 EuroSkinGraft) under grant agreement No. 279024 and the People Programme 'MultiTERM' (FP7-PEOPLE-2008-ITN) under grant agreement no. 238551, as well as from 'iTERM' (FP7-PEOPLE-2013-ITN) under grant agreement no. 607868. We are particularly grateful to the Fondation Gaydoul and the sponsors of 'Dona Tissue' for their generous financial support and interest in our work. The funding sources did not participate in the study design, the collection, analysis and interpretation of data, the writing of the report, or the decision to submit the article for publication.

\section{Disclosure Statement}

Conflicts of interest: none.

\section{References}

$>1$ Schiestl C, Neuhaus K, Biedermann T, BöttcherHaberzeth S, Reichmann E, Meuli M: Novel treatment for massive lower extremity avulsion injuries in children: slow, but effective with good cosmesis. Eur J Pediatr Surg 2011;21:106-110.

$>$ Boekema BKHL, Vlig M, Olde Damink L, Middelkoop E, Eummelen L, Bühren A V, et al: Effect of pore size and cross-linking of a novel collagen-elastin dermal substitute on wound healing. J Mater Sci Mater Med 2014;25:423-433.
- 3 Bloemen MCT, van Leeuwen MCE, van Vucht NE, van Zuijlen PPM, Middelkoop E: Dermal substitution in acute burns and reconstructive surgery: a 12-year follow-up. Plast Reconstr Surg 2010;125:1450-1499.

4 Hur G-Y, Seo D-K, Lee J-W: Contracture of skin graft in human burns: effect of artificial dermis. Burns 2014; 40:1497-1503.
5 Böttcher-Haberzeth S, Biedermann T, Schiestl C, Hart-
mann-Fritsch F, Schneider J, Reichmann E, et al: Mat-
riderm ${ }^{\circledR} 1 \mathrm{~mm}$ versus Integra ${ }^{\circledR}$ Single Layer $1.3 \mathrm{~mm}$
for one-step closure of full thickness skin defects: a
comparative experimental study in rats. Pediatr Surg
Int 2012: 171-177.
6 Jeng JC, Fidler PE, Sokolich JC, Jaskille AD, Khan S,
White PM, et al: Seven years' experience with Integra
as a reconstructive tool. J Burn Care Res;28:120-126. 
7 Nguyen DQA, Potokar TS, Price P: An objective longterm evaluation of Integra (a dermal skin substitute) and split thickness skin grafts, in acute burns and reconstructive surgery. Burns 2010;36:23-28.

$>$ Schiestl C, Stiefel D, Meuli M: Giant naevus, giant excision, eleg(i)ant closure? Reconstructive surgery with Integra Artificial Skin to treat giant congenital melanocytic naevi in children. J Plast Reconstr Aesthet Surg 2010;63:610-615.

9 Stiefel D, Schiestl C, Meuli M: Integra Artificial Skin for burn scar revision in adolescents and children. Burns 2010;36:114-120.

10 Ryssel H, Radu CA, Germann G, Otte M, Gazyakan E: Single-stage Matriderm ${ }^{\circledR}$ and skin grafting as an alternative reconstruction in high-voltage injuries. Int Wound J 2010;7:385-392.

11 Ryssel H, Germann G, Czermak C, Kloeters O, Gazyakan E, Riedel K: Matriderm ${ }^{\circledR}$ in depth-adjusted reconstruction of necrotising fasciitis defects. Burns 2010;36: 1107-1111.

12 Biedermann T, Klar AS, Böttcher-Haberzeth S, Schiestl C, Reichmann E, Meuli M: Tissue-engineered dermo-epidermal skin analogs exhibit de novo formation of a near natural neurovascular link 10 weeks after transplantation. Pediatr Surg Int 2014;30:165-172.

13 Klar AS, Böttcher-Haberzeth S, Biedermann T, Michalak K, Kisiel M, Reichmann E, et al: Differential expression of granulocyte, macrophage, and hypoxia markers during early and late wound healing stages following transplantation of tissue-engineered skin substitutes of human origin. Pediatr Surg Int 2014;30: $1257-1264$.

14 Hartmann-Fritsch F, Biedermann T, Braziulis E, Luginbühl J, Pontiggia L, Böttcher-Haberzeth S, et al: Collagen hydrogels strengthened by biodegradable meshes are a basis for dermo-epidermal skin grafts intended to reconstitute human skin in a one-step surgical intervention. J Tissue Eng Regen Med 2016;10:81-91.

15 ClinicalTrials.gov: Phase I Study for Autologous Dermal Substitutes and Dermo-epidermal Skin Substitutes for Treatment of Skin Defects. https://clinicaltrials.gov/ ct2/show/NCT02145130?term $=$ denovoSkinerank $=1$ (last accessed August 22, 2016)

16 Regulation (EC) No 1394/2007 of the European Parliament and of the Council of 13 November 2007 on Advanced Therapy Medicinal Products and Amending Directive 2001/83/EC and Regulation (EC) No 726/2004 Off J Eur Union 2007.

17 Commission Directive 2003/94/EC of 8 October 2003 laying down the principles and guidelines of good manufacturing practice in respect of medicinal products for human use and investigational medicinal products for human use. Off J Eur Union 2003.

18 Mansnérus J: Encountering Challenges with the EU Regulation on Advance Therapy Medical Products. Eur J Health Law 2015;22:426-461.

19 Voltz-Girolt C, Celis P, Boucaumont M, D’Apote L, Pinheiro M-H, Papaluca-Amati M: The advanced therapy classification procedure. Overview of experience gained so far. Bundesgesundheitsbl Gesundheitsforsch Gesundheitsschutz 2011;54:811-815.

20 Pirnay J-P, Vanderkelen A, De Vos D, Draye J-P, Rose $\mathrm{T}$, Ceulemans C, et al: Business oriented EU human cell and tissue product legislation will adversely impact Member States' health care systems. Cell Tissue Bank 2013;14:525-560.

21 European Medicines Agency, CAT Secretariat \& US Food and Drug Administration. Regen Med 2011;6(6 suppl):90-96.

22 Pearce KF, Hildebrandt M, Greinix H, Scheding S, Koehl U, Worel N, et al: Regulation of advanced therapy medicinal products in Europe and the role of academia. Cytotherapy 2014;16:289-297.
23 Apligraf ${ }^{\circledR}:$ www.apligraf.com/ (last accessed August 22, 2016).

24 Nyame TT, Chiang HA, Leavitt T, Ozambela M, Orgill DP: Tissue-engineered skin substitutes. Plast Reconstr Surg 2015;136:1379-1388.

25 Tiscover ${ }^{\circledR}$ http://a-skin.nl/wound-healing-products/tiscover/. (last accessed August 22, 2016).

26 European Medicines Agency: ICH Guideline Q9 on Quality Risk Management. www.ich.org/fileadmin/Public_Web_Site/ICH_Products/Guidelines/Quality/Q9/ Step4/Q9_Guideline.pdf. (last accessed August 22, 2016).

27 Lux A, Mawo De Bikond J, Etienne A, QuillerouGrivot E: FMEA and consideration of real work situations for safer design of production systems. Int J Occup Saf Ergon 201631;1-8.

28 Stamatis DH: Failure Mode and Effect Analysis: FMEA from Theory to Execution, 2nd ed. Milwaukee, American Society for Quality Press, 2003.

29 FMEA Info Centre. $w w w$.fmeainfocentre.com/ (last accessed August 22, 2016).

30 EudraLex - The Rules Governing Medicinal Products in the European Union. Volume 4: Good Manufacturing Practice Medicinal Products for Human and Veterinary Use - Chapter 4:Documentation 2010. http://ec.europa.eu/health/documents/eudralex/vol-4/ index_en.htm/ (last accessed August 22, 2016).

31 EudraLex - The Rules Governing Medicinal Products in the European Union. Volume 4: EU Guidelines for Good Manufacturing Practice for Medicinal Products for Human and Veterinary Use - Chapter 1:Pharmaceutical Quality System 2012. http://ec.europa.eu/health/ documents/eudralex/vol-4/index_en.htm/ (last accessed August 22, 2016)

32 Detailed Guidance for the Request for Authorisation of a Clinical Trial on a Medicinal Product for Human Use to the Competent Authorities, Notification of Substantial Amendments and Declaration of the End of the Trial. 2005. http://ec.europa.eu/health/files/pharmacos/ docs/doc2005/10_05/ca_14-2005_en.pdf (last accessed August 22, 2016).

33 Richtlinie 2006/17/EG der Kommission vom 8. Februar 2006 zur Durchführung der Richtlinie 2004/23/ EG des Europäischen Parlaments und des Rates hinsichtlich technischer Vorschriften für die Spende, Beschaffung und Testung von menschlichen Geweben und Zellen. Amtsblatt der Europäischen Union 2006.

34 Council of Europe: European Pharmacopoeia 5.2.8: Minimising the risk of transmitting animal spongiform encephalopathy agents via human and veterinary medicinal products; in European Pharmacopoeia, 8th ed. www.edqm.eu/en/european-pharmacopoeia-8thedition-1563.html (last accessed August 22, 2016).

35 Council of Europe: European Pharmacopoeia Monograph 1483: Products with risk of transmitting agents of animal spongiform encephalopathies; in : European Pharmacopoeia, 8th ed. www.edqm.eu/en/europeanpharmacopoeia-8th-edition-1563.html (last accessed August 22, 2016).

36 EudraLex - The Rules Governing Medicinal Products in the European Union. Volume 4:EU Guidelines for Good Manufacturing Practice for Medicinal Products for Human and Veterinary Use Part 1 - Chapter 6:Quality Control 2014. http://ec.europa.eu/health/ documents/eudralex/vol-4/index_en.htm/ (last accessed August 22, 2016).

37 European Pharmacopoeia 5.1.1: Methods of preparation of sterile products; in : European Pharmacopoeia. EDQM Council of Europe.

38 Rutala WA, Weber DJ, Committee HICPA: Guideline for Disinfection and Sterilization in Healthcare Facilities 2008;
39 EudraLex - The Rules Governing Medicinal Products in the European Union. Volume 4:EU Guidelines to Good Manufacturing Practice Medicinal Products for Human and Veterinary Use - Annex 1:Manufacture of Sterile Medicinal Products. http://ec.europa.eu/health/ documents/eudralex/vol-4/index_en.htm/ (last accessed August 22, 2016).

40 Council of Europe: European Pharmacopoeia 2.6.1: Sterility; in European Pharmacopoeia, 8th ed. www. edqm.eu/en/european-pharmacopoeia-8th-edition-1563. html (last accessed August 22, 2016).

41 European Pharmacopoeia 2.6.7:Mycoplasmas; in European Pharmacopoeia, 8th ed. www.edqm.eu/en/european-pharmacopoeia-8th-edition-1563.html (last accessed August 22, 2016)..

42 United States Pharmacopeial Convention 63: Mycoplasma Test.

43 Council Europe: European Pharmacopoeia 2.6.14:Bacterial Endotoxins; in European Pharmacopoeia, 8th ed. www.edqm.eu/en/european-pharmacopoeia-8thedition-1563.html (last accessed August 22, 2016).

44 United States Pharmacopeial Convention 85: Bacterial Endotoxins Test.

45 EudraLex - The Rules Governing Medicinal Products in the European Union. Volume 4:EU Guidelines for Good Manufacturing Practice for Medicinal Products for Human and Veterinary Use Part 1 - Chapter 2:Personnel. http://ec.europa.eu/health/documents/eudralex/ vol-4/index_en.htm/ (last accessed August 22, 2016).

46 Committee for Medicinal Products for Human Use: Guideline on the Requirements to the Chemical and Pharmaceutical Quality Documentation Concerning Investigational Medicinal Products in Clinical Trials. 2006. http://ec.europa.eu/health/files/eudralex/vol-10/ 18540104en_en.pdf (last accessed August 22, 2016).

47 Directive 2001/20/EC of the European Parliament and of the Council of 4 April 2001 on the Approximation of the Laws, Regulations and Administrative Provisions of the Member States Relating to the Implementation of Good Clinical Practice in the Conduct of Trials on Medicinal Products for Human Use. www.eortc.be/ services/doc/clinical-eu-directive-04-april-01.pdf (last accessed August 22, 2016).

48 Swissmedic: Clinical Trials www.swissmedic.ch/bewilligungen/00155/00242/index.html?lang=en (last accessed August 22, 2016).

49 European Medicines Agency: ICH Guideline E6: Good Clinical Practice. Consolidated Guideline. www.hc-sc. gc.ca/dhp-mps/prodpharma/applic-demande/guide-ld/ ich/efficac/e6-eng.php (last accessed August 22, 2016).

50 European Medicines Agency: http://www.ema.europa.eu

51 Mak IW, Evaniew N, Ghert M: Lost in translation: animal models and clinical trials in cancer treatment. Am J Transl Res 2014;6:114-118.

52 Böttcher-Haberzeth S, Biedermann T, Klar AS, Widmer DS, Neuhaus K, Schiestl C, et al: Characterization of pigmented dermo-epidermal skin substitutes in a long-term in vivo assay. Exp Dermatol 2015;24:16-21.

53 Braziulis E, Biedermann T, Hartmann-Fritsch F, Schiestl C, Pontiggia L, Böttcher-Haberzeth S, et al: Skingineering I: Engineering porcine dermo-epidermal skin analogues for autologous transplantation in a large animal model. Pediatr Surg Int 2011;27:241-247.

54 Schiestl C, Biedermann T, Braziulis E, HartmannFritsch F, Böttcher-Haberzeth S, Arras M, et al: Skingineering II: Transplantation of large-scale laboratorygrown skin analogues in a new pig model. Pediatr Surg Int 2011;27:249-254.

55 NIH: Phase I Trials www.nlm.nih.gov/services/ctphases. html (last accessed August 22, 2016).

56 FDA: FDA and Clinical Drug Trials: A Short History www.fda.gov/AboutFDA/WhatWeDo/History/Overviews/ ucm304485.htm (last accessed August 22, 2016). 
57 EuroSkinGraft: www.euroskingraft.eu/ (last accessed August 22, 2016).

58 Wyss Translational Center Zurich: www.wysszurich. uzh.ch/ (last accessed August 22, 2016).

59 Hall AK, Carlson MR: The current status of orphan drug development in Europe and the US. Intractable Rare Dis Res 2014;3:1-7.

60 Regulation (EC) No 141/2000 of the European Parliament and of the Council of 16 December 1999 on Orphan Medicinal Products. http://ec.europa.eu/health/ files/eudralex/vol-1/reg_2000_141/reg_2000_141_en. pdf (last accessed August 22, 2016).
61 Dermagraft ${ }^{\circledR}$. www.dermagraft.com/portal/ (last accessed August 22, 2016).

62 FirstCover. www.elanix.ch/ (last accessed August 22, 2016).

63 Epicel $^{\circledR}$. http://epicel.com/ (last accessed August 22, 2016).

64 Engineered Skin Substitute. www.amarantus.com/ therapeutics-pipeline/regenerative-medicine/engineeredskin-substitute-ess (last accessed August 22, 2016).

65 Engineered Skin Substitute. https://clinicaltrials.gov/ ct2/show/NCT01655407?term=ess + skin \& rank $=1$ (last accessed August 22, 2016).
66 Tiscover ${ }^{\circledR}$. https://clinicaltrials.gov/ct2/show/NCT0236 0358?term $=$ tiscoverひrank $=1$

67 Self-Assembled Skin Substitute. www.chudequebec.ca/ accueil.aspx (last accessed August 22, 2016).

68 Self-Assembled Skin Substitute. https://clinicaltrials. gov/ct2/show/NCT02350205? term $=$ quebec+skiner $r$ ank $=1$ (last accessed August 22, 2016) 